\title{
Catatan Managing Editor: Manusia, lingkungan, dan interaksi keduanya
}

\author{
Joevarian Hudiyana* \\ Fakultas Psikologi, Universitas Indonesia, Depok, Jawa Barat
}

Salam sejahtera,

Pada awal tahun baru ini, terjadi perubahan struktural yang sangat penting di Jurnal Psikologi Sosial (JPS). Kami selaku tim manajerial JPS mengucapkan selamat atas terpilihnya Dekan Fakultas Psikologi Universitas Indonesia periode 2022 sampai dengan 2026, Dr. Bagus Takwin, M.Hum. Sebelumnya, beliau menjabat sebagai kepala editor atau chief editor dari JPS sejak tahun 2017. Kami juga mengucapkan selamat kepada Bapak Dicky Pelupessy, Ph.D, salah satu dewan editor JPS, atas jabatannya sebagai Wakil Dekan Bidang Pendidikan, Penelitian dan Kemahasiswaan di Fakultas Psikologi Universitas Indonesia. Dengan demikian, Mas Aten dan Mas Dicky-begitu mereka biasanya disapa secara akrab-tetap berada di JPS sebagai dewan editor. Kami selaku tim manajerial JPS mengucapkan selamat atas terpilihnya Dr. Mirra Noor Milla dari Universitas Indonesia sebagai kepala editor baru JPS. Sebelumnya, beliau adalah salah satu dewan editor di JPS. Sebagaimana para penggiat dan ilmuwan psikologi sosial di Indonesia ketahui, Mbak Mirra-begitu biasanya ia disapa di kampus-adalah pakar terorisme Indonesia. Karya-karya beliau dalam memahami tindakan terorisme dan rehabilitasi terhadap teroris di Indonesia cukup monumental dan bermanfaat dalam mencegah dan mengintervensi psikologi dari teroris.

Berbagai karya beliau sudah dipublikasikan di jurnal internasional. Diantara karya-karya beliau adalah usaha dalam memahami struktur jejaring kelompok teror dengan peran pimpinan teroris mungkin berbeda antar peran (dipublikasikan dalam jurnal Frontiers in Psychology lihat Milla dkk., 2020a), faktor-faktor kebermaknaan hidup, relasi, dan identitas seseorang dibalik aksi teror dan komitmen terhadap kelompok teror (dipublikasikan dalam beberapa jurnal internasional seperti Asian Journal of Social Psychology dan Peace \& Conflict: Journal of Peace Psychology - lihat Milla dkk., 2013; 2019; Yustisia dkk., 2020), serta usaha rehabilitasi teroris (dipublikasikan dalam Asian Journal of Social Psychology - lihat Milla dkk., 2020b, Muluk dkk., 2020).

JPS juga menyambut kedatangan dewan editor baru, yaitu Bapak Omar Khalifa Burhan,
Ph.D dari Program Studi Psikologi, Universitas Sumatera Utara. Beliau meraih Ph.D dari Universiteit Leiden pada tahun 2020. Riset-riset beliau telah dipublikasikan dalam jurnal internasional seperti studi memahami perilaku nepotisme dan keadilan (dipublikasikan di jurnal Organizational Behavior and Human Decision Processes - lihat Burhan dkk., 2020), dan perilaku prososial terhadap imigran (dipublikasikan di Journal of Social Issues dan Asian Journal of Social Psychology lihat Burhan \& van Leeuwen, 2016; Mashuri dkk., 2013). Kami yakin kepakaran beliau dalam topik keadilan dan perilaku prososial sangat substansial dalam membantu JPS.

Pada edisi Februari 2022 ini, kami mempublikasikan tujuh naskah. Naskah-naskah ini spesifiknya membahas mengenai interaksi manusia dengan lingkungannya, termasuk juga masalah COVID-19 yang merupakan dampak dari interaksi tersebut. Tiga naskah pertama berusaha memahami konteks pandemi COVID-19. Ini merupakan tiga naskah pertama dari seri khusus respon terhadap COVID-19 pada tahun 2022. Naskah pertama ditulis oleh Marina dkk berjudul "Adaptasi individual dan kolektif: Respon masyarakat Indonesia menghadapi pandemi COVID-19". Naskah ini berusaha mengeksplorasi adaptasi manusia dalam situasi baru pandemi. Strategi solidaritas di level kolektif ternyata prevalen dan ini semakin memperkuat asumsi dan perspektif teori bahwa masa krisis akan mengeluarkan malaikat-malaikat dalam diri manusia.

Naskah kedua ditulis oleh Intan dkk. berjudul "Sosiodemografi dan tingkat kecemasan mahasiswa pada masa pandemi COVID-19". Dalam riset ini, ditemukan bahwa lingkungan geografis konteks urban (vs. rural) serta jejaring sosial berhubungan dengan kecemasan mahasiswa di era pandemi. Naskah ini memberikan kontribusi mengenai faktor sosiodemografis yang berperan dalam kesehatan mental di masa pandemi.

Naskah ketiga ditulis oleh Pratiwi berjudul "Mediasi media dan disiplin digital pada anak usia dini saat pandemi COVID-19". Sebagaimana naskah sebelumnya, lingkungan digital menjadi dimensi yang tidak bisa diabaikan dan perlu dipahami psikologi sosial. Dalam situasi pandemi, interaksi anak dengan gawai menjadi topik yang substansial dan naskah ini menemukan bagai- 
mana orangtua umumnya mengontrol interaksi anak dengan gawai.

Naskah keempat ditulis oleh Prasetyo dan Purba berjudul "Kepemimpinan paternalistik dan perilaku keselamatan kerja: Kepercayaan terhadap supervisor sebagai mediator". Naskah ini menyoroti bahwa interaksi manusia dengan lingkungan kerja juga perlu memperhatikan faktor kepemimpinan. Rasa percaya terhadap pemimpin, yang merupakan buah dari kepemimpinan paternalistik menjadi faktor penting timbulnya perilaku keselamatan di lingkungan kerja.

Naskah kelima ditulis oleh Mashoedi dan Pekerti berjudul "Apakah phubbing mengganggu pertemanan? Hubungan phubbing dengan kepuasan pertemanan pada orang beranjak dewasa". Phubbing atau perilaku mengabaikan interaksi sosial karena terdistraksi atau terfokus pada gawai merupakan perilaku yang relevan dibicarakan pada dekade terakhir. Perilaku tersebut dikatakan mengganggu interaksi sosial, tapi apakah perilaku tersebut dapat merusak pertemanan seseorang? Riset ini berusaha mendemonstrasikan apakah perilaku phubbing memang destruktif ataukah itu menjadi sesuatu yang wajar di masa kini.

Naskah keenam berjudul "Manusia dan Lingkungan Alam: Analisis Faktor Konfirmatori terhadap Nature Relatedness Scale bahasa Indonesia", ditulis oleh Yofana dan Djuwita. Naskah ini berusaha mengadaptasi konstruk nature relatedness yang berangkat dari hipotesis biofilia - bahwa manusia memiliki dorongan mendasar untuk selalu dekat dengan alam dan lingkungan. Sayangnya, masih belum banyak penelitian terkait ini padahal konstruk ini penting dalam memahami manusia dan interaksinya dengan alam. Diharapkan dengan hadirnya adaptasi skala untuk konstruk tersebut, akan menstimulasi riset-riset terkait interaksi manusia dengan lingkungan hijau.

Terakhir adalah naskah yang ditulis oleh Febriana dkk. berjudul "Adaptasi dan validasi skala stres peran (role stressor scale) dalam bahasa dan budaya Indonesia dengan confirmatory factor analysis". Individu memiliki peran secara sosial dan peranan-peranan ini hampir tidak bisa dilepaskan dari kehidupan manusia dalam bermasyarakat atau dengan lingkungannya. Namun demikian, usaha dalam memahami peranan itu juga perlu melihat aspek stress terkait peran. Alat ukur yang diadaptasi dan divalidasi para penulis menjadi instrumen yang penting agar bisa digunakan para peneliti di Indonesia.

Kami berharap naskah-naskah tersebut menstimulasi berbagai riset-riset lanjutan, khususnya dalam tema interaksi manusia dan lingkungan serta perilaku manusia di tengah konteks pandemi. Kami juga berharap naskahnaskah tersebut berguna dalam pengembangan ilmu pengetahuan, khususnya psikologi sosial di Indonesia.

Mewakili tim manajerial JPS, Dr. Joevarian Hudiyana

\section{Referensi}

Burhan, O. K., \& van Leeuwen, E. (2016). Altering perceived cultural and economic threats can increase immigrant helping.Journal of Social Issues, 72(3), 548-565. https://doi.org/10.1111/josi.12181

Burhan, O. K., van Leeuwen, E., \& Scheepers, D. (2020). On the hiring of kin in organizations: Perceived nepotism and its implications for fairness perceptions and the willingness to join an organization. Organizational Behavior and Human Decision Processes, 161, 34-48. https://doi.org/10.1016/j.obhdp.2020.03. 012

Mashuri, A., Burhan, O. K., \& van Leeuwen, E. (2013). The impact of multiculturalism on immigrant helping. Asian Journal of Social Psychology, 16(3), 207-212. https://doi.org/10.1111/ajsp.12009

Milla, M. N., Faturochman, \& Ancok, D. (2013). The impact of leader-follower interactions on the radicalization of terrorists: A case study of the Bali bombers. Asian Journal of Social Psychology, 16(2), 92-100. https://doi.org/10.1111/ajsp.12007

Milla, M. N., Hudiyana, J., Cahyono, W., \& Muluk, H. (2020a). Is the role of ideologists central in terrorist networks? A social network analysis of Indonesian terrorist groups. Frontiers in psychology, 11, 333. https://doi.org/10.3389/fpsyg.2020.0033 3

Milla, M. N., Hudiyana, J., \& Arifin, H. H. (2020b). Attitude toward rehabilitation as a key predictor for adopting alternative identities in deradicalization programs: An investigation of terrorist detainees' profiles. Asian Journal of Social Psychology, 23(1), 1528. https://doi.org/10.1111/ajsp.12380

Milla, M. N., Putra, I. E., \& Umam, A. N. (2019). Stories from jihadists: Significance, identity, and radicalization through the call for jihad. Peace and Conflict: Journal of Peace Psychology, 25(2), 111. https://doi.org/10.1037/pac0000371

Muluk, H., Umam, A. N., \& Milla, M. N. (2020). Insights from a deradicalization program in Indonesian prisons: The potential benefits of psychological intervention prior to ideological discussion. Asian Journal of 
Social Psychology, 23(1), 42-53. https://doi.org/10.1111/ajsp.12392

Yustisia, W., Shadiqi, M. A., Milla, M. N., \& Muluk, H. (2020). An investigation of an Expanded Encapsulate Model of Social Identity in Collective Action (EMSICA) including perception of threat and intergroup contact to understand support for Islamist terrorism in Indonesia. Asian Journal of Social Psychology, 23(1), 29-41. https://doi.org/10.1111/ajsp.12372 